\title{
Compra institucional de produtos da agricultura familiar: avaliando a execução do Programa de Aquisição de Alimentos pelas universidades federais
}

\author{
Institutional purchase of family farm products: evaluating the \\ execution of the Food Acquisition Program by federal universities \\ Rafael Junior dos Santos Figueiredo Salgado (D), Washington José de Souza (D), \\ Marco Aurélio Marques Ferreira² (1)
}

\begin{abstract}
'Programa de Pós-graduação em Administração, Centro de Ciências Sociais Aplicadas, Universidade Federal do Rio Grande do Norte (UFRN), Natal (RN), Brasil. E-mails: rafa.salgad@gmail.com; wsufrn@gmail.com

${ }^{2}$ Programa de Pós-graduação em Administração, Centro de Ciências Humanas, Universidade Federal de Viçosa (UFV), Viçosa (MG), Brasil. E-mail: marcoufv1@gmail.com
\end{abstract}

\begin{abstract}
Como citar: Salgado, R. J. S. F., Souza, W. J., \& Ferreira, M. A. M. (2022). Compra institucional de produtos da agricultura familiar: avaliando a execução do Programa de Aquisição de Alimentos pelas universidades federais. Revista de
\end{abstract} Economia e Sociologia Rural, 60(spe), e248030. https://doi.org/10.1590/1806-9479.2021.248030

Resumo: $O$ objetivo é avaliar o estágio de conformidade das universidades federais brasileiras ao requisito da aquisição de produtos da agricultura familiar nos termos do Decreto n 7.775/2012, delimitando alcances e dilemas para retroalimentar o Programa de Aquisição de Alimentos na modalidade Compra Institucional (PAA-CI). Tratase de estudo qualitativo-descritivo, com análise de dados secundários (chamadas públicas e resultados) entre 2012 e 2019. A análise dos dados indicou que é limitada e heterogênea a execução do PAA-CI no abastecimento de alimentos para os restaurantes universitários via chamadas públicas, beneficiando um reduzido número de agricultores familiares. Há lacunas em termos de cobertura do Programa e falhas na elaboração das chamadas públicas, o que desestimula a participação dos agricultores familiares e das organizações da agricultura familiar, especialmente dos menos estruturados. Em virtude do caráter recente da legislação, devem ser fomentadas políticas públicas de assistência técnica e extensão rural para a agricultura familiar e ações de capacitação dos gestores públicos de modo a conduzir burocratas a interações com organizações locais, criando e aperfeiçoando fluxos de informações e conhecimentos e retroalimentando políticas públicas de desenvolvimento local integradas às atividades-fim das universidades, de ensino, pesquisa e extensão.

Palavras-chave: compras públicas, agricultura familiar, mercados institucionais, compra institucional.

\begin{abstract}
This study aims to assess the level of compliance of Brazilian federal universities with the requirement for the acquisition of products from family farming under Decree No. 7775/2012, delimiting scopes and dilemmas to provide feedback to the Food Acquisition Program in the Institutional Purchase modality (PAACI). This is a descriptive qualitative study, with an analysis of secondary data (calls and results) between 2012 and 2019. Data analysis indicated that the implementation of the PAA-CI in the supply of food to university restaurants via public calls is limited and heterogeneous, benefiting a small number of family farmers. There are gaps in terms of Program coverage and failures in the preparation of public notices, which discourages the participation of family farmers and family farming organizations, especially the less structured ones. Due to the recent nature of the legislation, public policies of technical assistance and rural extension for family farming and actions to train public managers must be promoted to lead bureaucrats to interactions with local organizations, creating and improving flows of information and knowledge and providing feedback public policies for local development integrated to the core activities of universities, teaching, research, and extension.
\end{abstract}

Keywords: public purchases, family farming, institutional markets, institutional purchasing.

\section{Introdução}

Demandas demográficas e alimentares estão entre os maiores desafios enfrentados pela humanidade neste século XXI, especialmente nas grandes cidades e nos espaços urbanos. Diante desses desafios, o poder público vem despertando para o potencial de alimentos 
saudáveis como elo de conexão entre saúde pública, meio ambiente e desenvolvimento social equitativo e sustentável (Schneider et al., 2016). Nesse quesito, destaca-se o Programa de Aquisição de Alimentos (PAA), iniciativa do Governo Federal brasileiro que adquire alimentos diretamente da agricultura familiar por meio de órgãos públicos nos níveis municipal, estadual e federal, destinando-os a unidades de educação, assistência social, segurança, justiça, saúde e organizações não governamentais.

O PAA é uma ação governamental que se insere nas políticas públicas de segurança alimentar e nutricional (SAN) e de fortalecimento da agricultura familiar, instituído pela Lei Federal $n^{\circ} 10.696$, de 2 de julho de 2003, e que tem o objetivo de fomentar a comercialização de produtos da agricultura familiar via compras governamentais. Ao eleger a agricultura familiar como protagonista do abastecimento de mercados institucionais, o PAA se apresenta como medida de indução de dinâmica de desenvolvimento rural e territorial que viabiliza a inclusão social, a segurança alimentar, o combate à pobreza e a redução de desigualdades (Dias et al., 2013; Anjos \& Becker, 2014). O Programa contribui para a geração de renda e, complementarmente, a melhoria das condições de alimentação de pessoas que se encontram em situação de vulnerabilidade social ou em situação de insegurança alimentar. A fome e a insegurança alimentar e nutricional são temas recorrentes no Brasil e no mundo, e, desse modo, a agricultura familiar tem papel importante na erradicação desse flagelo (Food and Agriculture Organization, 2020; Peraci \& Bittencourt, 2010).

As oportunidades viabilizadas pelo PAA foram potencializadas pela inclusão da modalidade Compra Institucional $(\mathrm{Cl})$, que passou a permitir aos órgãos de administração direta e indireta da União e de estados, Distrito Federal e municípios a compra de produtos da agricultura familiar com dispensa de licitação, por meio de chamada pública nos termos do Decreto n 7.775/2012. Essa modalidade de compra pública passou a viabilizar aquisições de alimentos, por exemplo, por hospitais, quartéis, presídios, restaurantes universitários, refeitórios de creches, escolas filantrópicas e todo o conjunto de organizações de interesse público não governamentais. Outra inovação importante foi estabelecida pelo Decreto n 8.473/2015, presente no Plano Safra da Agricultura Familiar 2015/2016, que determinou a aplicação de recursos para a compra de alimentos da agricultura familiar em, no mínimo, 30\%, para todos os órgãos da União a partir de 2016. Essas ações ampliaram expressivamente $\mathrm{o}$ alcance da $\mathrm{Cl}$ da agricultura familiar pelo acesso do segmento a um mercado potencial de $R \$ 7$ bilhões anuais (Brasil, 2018). Essas iniciativas do Governo Federal têm estimulado os governos estaduais a criar seus próprios mecanismos de compras públicas, a exemplo dos estados de Minas Gerais (Lei Estadual $n^{\circ}$ 20.608/2013) e do Rio Grande do Norte (Lei Estadual n 10.536/2019), e as organizações da agricultura familiar a demandar e construir novos mercados públicos e privados.

Além da possibilidade de expansão, as inovações implantadas fortaleceram políticas públicas para a agricultura familiar, não apenas por tornar obrigatória a utilização de no mínimo 30\%, mas também por instituir a vinculação orçamentária para tal propósito. Essa é uma inovação que diz respeito à legislação das aquisições públicas brasileiras. Se, até então, todas as compras estavam sob a obrigatoriedade de seguir preceitos legais de isonomia e concorrência, abriu-se um precedente histórico para o fornecedor caracterizado como "agricultor familiar", mediante dispensa de processo licitatório.

A criação e a garantia de compra pela modalidade $\mathrm{Cl}$, em tese, proporcionou ao segmento da agricultura familiar a segurança de não mais depender de iniciativa governamental por tempo determinado, o que ocasionava dúvidas quanto ao fluxo de produção e comercialização e aos investimentos necessários para fornecer alimentos em qualidade, quantidade e regularidade demandados por instituições (Mielitz, 2014). No que concerne à implementação, havia ocorrido 
escassas iniciativas de compras governamentais da agricultura familiar por órgãos federais até a obrigatoriedade do mínimo de 30\% pelo PAA, a partir da modalidade Cl, em 2012.

O modelo de compras de alimentos dominante na maior parte das organizações públicas, pautado no processo licitatório, seguia a lógica da produção em massa, caracterizada por cadeias longas de abastecimento e por concepções de qualidade padronizadas e convencionais, determinando uma relação distante entre consumo e produção (Triches \& Schneider, 2010). Para a administração pública, o PAA-CI representou inovação no processo de compra de gêneros alimentícios, que se concentrava em grandes empresas/indústrias fornecedoras via aquisição em processo de licitação pública e pregão eletrônico, inviabilizando a participação da agricultura familiar local e regional por causa da impossibilidade de competição em condições equitativas (Assis, 2016).

Evidenciadas a importância e as recentes inovações do PAA, este artigo toma como objeto o cenário institucional de compras de alimentos da agricultura familiar por órgãos governamentais no Brasil com recorte no PAA-CI. Tem como objetivo avaliar o estágio de conformidade das universidades federais brasileiras ao requisito da aquisição de produtos da agricultura familiar, nos termos do Decreto $n^{\circ} 7.775 / 2012$, delimitando alcances e dilemas para retroalimentar 0 Programa. Para tanto, utiliza modelo analítico desenvolvido por Salgado (2020).

Dados sistematizados por Salgado (2020) indicam que, de um total de 63 universidades federais brasileiras, apenas 19 implementaram o PAA-Cl até 2019, mesmo após a entrada em vigor da Lei $n^{\circ} 8.473$. Contudo, até o momento, poucos estudos investigaram o processo de implementação das compras locais pelo PAA-Cl (Salgado et al., 2020). Deve-se, portanto, considerar que o PAA-Cl é de 2012, e o processo de operacionalização gera ainda dúvidas e insegurança entre agentes governamentais. Não havia, até 2019, registro de pesquisa analisando a execução do PAA-Cl pelas universidades federais, e, de modo genérico, são escassos os estudos voltados a explorar a execução nacional de chamadas públicas no Programa. Tal carência decorre, em parte, da complexidade do Programa, da dimensão geográfica do país e das dificuldades de se obter dados quantitativos (Kaminski et al., 2018). A presente pesquisa vem preencher uma lacuna na avaliação do PAA em esfera nacional, a partir da modalidade $\mathrm{Cl}$. Ao avaliar tal modalidade, em múltiplos aspectos, são pontuados desafios e indicadas alternativas, o que imputa relevância ao exercício efetivado.

Pesquisas com o viés aqui pautado disponibilizam resultados de avaliação de chamadas públicas no Programa Nacional de Alimentação Escolar (PNAE), a exemplo de Baccarin et al. (2017), Ferigollo et al. (2017) e Triches \& Silvestri (2018), que adotam o objeto de compras públicas em âmbito municipal. Ao abordar o PAA, a presente pesquisa difere tanto no foco quanto na competência administrativa, considerando que os critérios de execução (inclusive na definição de valores alocados por modalidade) se concentram no nível da regulação federal. Além disso, a presente pesquisa aborda compras públicas da agricultura familiar em âmbito nacional, com caráter censitário, adensando todas as chamadas públicas lançadas por universidades brasileiras entre 2012 e 2019, em todas as regiões brasileiras.

De outra forma, no âmbito do PAA, esta pesquisa é inovadora no que se refere à análise de origens e ao grau de processamento dos produtos, agroindustrialização e preço dos produtos, avançando ao abordar variáveis previstas em modelo lógico ${ }^{1}$ do PAA-CI (Salgado, 2020). Neste caso, estão em pauta variáveis como produção orgânica, cooperativismo, associativismo, SAN e cultura regional na agricultura familiar.

\footnotetext{
O modelo lógico é uma ferramenta sistemática e visual que pode ajudar a explicar, de forma simplificada, os fundamentos teóricos do Programa, que são frequentemente complexos, compreendendo diferentes tipos de componentes interligados, facilitando o planejamento, a comunicação e a tomada de decisão, além de gerar subsídios importantes para estruturar seu sistema de avaliação (Sambuichi et al., 2019; Savaya \& Waysman, 2005; W.K. Kellogg Foundation, 2004).
} 
É, pois, com base em instrumentos legais e no modelo lógico de Salgado (2020) que este artigo se mostra relevante. Por um lado, aborda o estágio em que se encontram as aquisições no PAA-Cl em instituições públicas federais, as quais, a princípio, detêm condições especiais para o cumprimento do marco legal supracitado, uma vez que as universidades são loci privilegiados no que se refere à geração e ao compromisso com a socialização de conhecimentos e à promoção de qualidade de vida e de desenvolvimento socioeconômico. Por outro lado, a presente pesquisa avalia se o Programa tem conseguido atingir os resultados esperados na modalidade $\mathrm{Cl}$, com recorte em organizações federais, além de lançar inquietações acerca de desafios inerentes, não apenas à execução do PAA-Cl, mas também a todo o conjunto de políticas públicas de fomento à agricultura familiar e ao desenvolvimento sustentável.

O exercício aqui realizado intenta responder à seguinte questão: em que medida as compras públicas da agricultura familiar por universidades federais se mostram em conformidade com os resultados esperados do PAA-CI? Para responder a tal questão, além desta introdução, o presente artigo aborda, na sequência, a importância do processo de avaliação de políticas públicas e os processos de aquisição de alimentos via PAA, focalizando a dinâmica de operacionalização da modalidade Cl. Trata-se, portanto, de um exercício de contextualização. Em seguida, são descritos os dados utilizados e a metodologia adotada na realização da pesquisa com dados secundários. Posteriormente, é analisado o desempenho das compras de alimentos da agricultura familiar com base em dados oficiais fornecidos pelas universidades federais, abarcando o período de $2012 \mathrm{a}$ 2019, para, então, levantar componentes de desempenho da política a partir de indicadores dos resultados previstos no modelo lógico. No tópico final, estão elencados os desafios e as perspectivas para a ampliação da compra de alimentos da agricultura familiar por parte das universidades federais brasileiras, bem como indicadas as possibilidades para pesquisas acadêmicas futuras.

\section{Avaliação de políticas públicas e sua importância}

Em função do caráter recente da legislação, análises da compra de alimentos da agricultura familiar são pertinentes considerando a necessidade de se acompanhar a aplicação e as contribuições da política para o fortalecimento da agricultura familiar, o estímulo a circuitos curtos de comercialização pela utilização de alimentos regionais, a valorização de hábitos alimentares locais e a promoção de SAN como diretrizes do PAA. Ademais, pesquisas são necessárias porque contribuem para o alcance de efetividade, eficácia e melhoria contínua do Programa, além de subsidiarem decisões de gestores públicos e órgãos governamentais na implementação. A abordagem deste artigo persegue tal propósito à luz do modelo explicativo ciclo político, por meio do qual determinada política pública pode ser examinada a partir de fases ou etapas: montagem da agenda, formação da política, tomada de decisão, implementação e avaliação (Howlett et al., 2012). Abordam-se aqui as fases de implementação e avaliação.

Implementação refere-se à fase em que regras, rotinas e processos sociais são convertidos de intenções em ações. É na implementação que são produzidos resultados concretos da política pública (O’Toole Junior, 2010). Análise do processo de implementação pode tomar a forma de pesquisa sobre a implementação (implementation research) ou de pesquisa avaliativa (evaluation research) (Secchi, 2013). A presente pesquisa se caracteriza como avaliativa, orientada para entender causas de falhas ou acertos das chamadas públicas em relação ao atendimento dos objetivos do PAA-Cl previstos no modelo lógico (Salgado, 2020).

A avaliação de políticas públicas, entendida como a análise sistemática do processo ou dos resultados de um programa ou de uma política, tem se tornado importante em centros de análise socioeconômica e universidades no Brasil, em decorrência da ampliação da escala e escopo 
da política social e, por conseguinte, em razão da necessidade de produção de informações específicas para o aprimoramento dos programas e ações governamentais (Januzzi, 2011). A avaliação tem potencial para aprimorar os resultados e a utilização e o controle racionais de recursos aplicados, fornecendo informações críticas aos formuladores de políticas sociais e gestores de programas para o desenho de políticas consistentes e eficazes e orientando-os em decisões e quesitos como continuidade, necessidade de correções ou mesmo suspensão de determinada política ou programa (Costa \& Castanhar, 2005).

Processos de aprendizagem política e administrativa se encontram em todas as fases do ciclo político, ou seja, a análise de eficiência, eficácia e efetividade não é necessariamente realizada ao final do processo político, mas sim pode e deve acompanhar as diversas fases a fim de indicar necessidades de adaptações permanentes e, com isso, viabilizar reformulações contínuas da política pública (Frey, 2000). Em virtude do processo recente de compras públicas da agricultura familiar pelas universidades federais e da importância socioeconômica que tais iniciativas assumem, tornando-se uma das principais fontes de renda para o segmento (Salgado, 2016), é pertinente conhecer o panorama da compra de alimentos provenientes da agricultura familiar, analisando o seu cumprimento em relação a objetivos e resultados esperados, o que aqui ocorre a partir do referido modelo lógico de Salgado (2020).

\section{Metodologia}

Trata-se de um estudo qualitativo, com análise de dados secundários (chamadas públicas e respectivos resultados) de universidades federais brasileiras. A pesquisa abarca o período de $2012 \mathrm{a}$ 2019. As informações preliminares referentes às universidades que já haviam formalizado a adesão ou estavam articulando a execução do PAA-Cl foram obtidas no Portal Compras da Agricultura Familiar do Ministério da Cidadania (MC) ou por solicitação dos pesquisadores à Secretaria Nacional de Inclusão Social e Produtiva Rural do MC. Por essas vias, a coleta resultou em 43 chamadas públicas de 17 universidades. Após a coleta de dados, as chamadas públicas foram obtidas no website do setor de compras das universidades ou via envio de e-mail aos gestores do PAA de cada instituição. Adicionalmente, foi realizada uma busca no Google com os descritores "chamada pública" e "universidade federal", retornando 2 universidades e mais 31 chamadas sem registros no MC.

Do total de 74 chamadas públicas coletadas, 9 foram excluídas por tratarem exclusivamente de compras no PNAE e 1 por ter sido cancelada. Restaram 64 chamadas públicas de 19 universidades federais das cinco regiões do Brasil. Desse total, 6 chamadas se referiam a credenciamento de organizações fornecedoras, apesar de não apresentarem algumas informações relevantes para a análise, como produtos demandados, e nos resultados apenas as organizações aptas a fornecer indicavam intenção de compra da agricultura familiar. As chamadas situam-se entre 2012 e 2019 e foram analisadas nas dimensões analíticas (Salgado, 2020), sintetizadas na Figura 1.

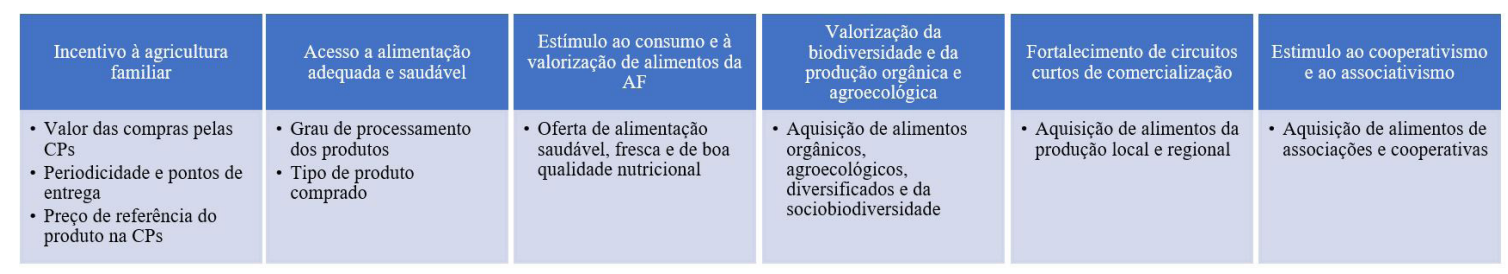

Figura 1 - Dimensões analíticas. Fonte: adaptada de Salgado (2020). 
Tal como indicado por Baccarin et al. (2017), na avaliação de compras públicas no PNAE, as chamadas públicas podem não se efetivar, ou se efetivar parcial ou totalmente, ou ainda sofrer alterações posteriormente. Por essa razão, na presente pesquisa, foram mapeados resultados das chamadas públicas no website das instituições. Entretanto, vários dados não se encontravam disponíveis nos sites das universidades, o que remete a limitações no processo administrativo de publicidade, monitoramento e controle. Nos casos de indisponibilidade de informações públicas, as instituições foram consultadas por e-mail e/ou telefone para coleta dos resultados das 64 chamadas públicas analisadas. A organização dos dados passou por tratamento de registros públicos, envolvendo a identificação e a eliminação de erros de digitação e ortográficos, além da padronização de detalhamentos e regionalismos que envolviam a designação de diversos produtos.

Após a obtenção dessas informações, os dados foram tabulados e analisados por meio do Microsoft Excel, a partir de estatística descritiva.

\subsection{Resultados e Discussão}

O PAA nas universidades federais: uma leitura nacional para o período 2012-2019

Os dados da Tabela 1 indicam uma restrita participação da agricultura familiar no fornecimento de alimentos às universidades federais brasileiras. No universo de 63 universidades federais brasileiras, apenas 19 (30\%) adquiriram alimentos da agricultura familiar por meio de chamadas públicas. A região Sul possuiu o melhor desempenho quando considerado o número de instituições - de 11 (45,5\%), 5 estavam executando ou haviam executado compras da agricultura familiar pelo PAA entre 2012 e 2019. O Centro-Oeste apresentou o menor percentual (20\%). Achado semelhante foi encontrado por Saraiva et al. (2013), ao analisarem as compras públicas da agricultura familiar pelos municípios no âmbito do PNAE.

Tabela 1 - Resultado percentual de execução do PAA-Cl por regiões e Brasil entre 2012 e 2019

\begin{tabular}{|c|c|c|c|c|c|c|c|c|c|c|c|c|}
\hline & \multicolumn{10}{|c|}{ Regiões brasileiras } & \multirow{2}{*}{\multicolumn{2}{|c|}{ Brasil }} \\
\hline & \multicolumn{2}{|c|}{ Sul } & \multicolumn{2}{|c|}{ Sudeste } & \multicolumn{2}{|c|}{ Nordeste } & \multicolumn{2}{|c|}{ Norte } & \multicolumn{2}{|c|}{$\begin{array}{l}\text { Centro- } \\
\text { Oeste }\end{array}$} & & \\
\hline & $\mathbf{n}$ & $\%$ & $\mathbf{n}$ & $\%$ & $\mathbf{n}$ & $\%$ & n & $\%$ & $\mathbf{n}$ & $\%$ & $\mathbf{n}$ & $\%$ \\
\hline Executou & 5 & 45,5 & 5 & 26,63 & 5 & 27,7 & 3 & 30 & 1 & 20 & 19 & 30,1 \\
\hline $\begin{array}{c}\text { Não } \\
\text { executou }\end{array}$ & 6 & 54,5 & 14 & 73,67 & 13 & 72,3 & 7 & 70 & 4 & 80 & 44 & 69,9 \\
\hline Total & 11 & 100 & 19 & 100 & 18 & 100 & 10 & 100 & 5 & 100 & 63 & 100 \\
\hline
\end{tabular}

A maior execução na região Sul pode estar relacionada à estrutura que lá assume o segmento da agricultura familiar. Estudo de Guilhoto et al. (2007) apontou que a agricultura familiar possuía expressiva participação no produto interno bruto das regiões Sul, Nordeste e Norte, enquanto a região Centro-Oeste apresentava características de grandes propriedades e ênfase na exportação. A região Sul destaca-se na produção da agricultura familiar e no abastecimento interno de alimentos. Portanto, o desempenho de compras públicas da agricultura familiar tende a reproduzir características sociais e estruturais do setor agrícola nacional, de tal modo que, em locais onde há maior expressão econômica, o segmento aparece integrado a mercados institucionais. A esse fato somam-se elevados níveis dos capitais físicos e sociais, incluindo os altos níveis de afiliação cooperativa, e capacidades de encaminhamento de reivindicações e de produção de volumes significativos de mercadorias (Baccarin et al., 2017; Saraiva et al., 
2013). Esse conjunto de qualidades explica o desempenho superior do Sul na execução total do PAA, com aproximadamente 34\% do volume de recursos aplicados no período de 2003 a 2013 (Companhia Nacional de Abastecimento, 2014).

A assimetria regional, com nítido destaque para a região Sul, é aqui abordada para reforçar a relevância dos serviços de assistência técnica e extensão rural (Ater) como requisito para a efetividade de ações públicas voltadas ao acesso do segmento da agricultura familiar a mercados institucionais. Dito de outro modo, se em outras regiões a capacidade de acesso a mercados institucionais é restrita, por parte do segmento da agricultura familiar, investimentos em serviços de Ater (públicos e privados), ainda que insuficientes por si sós, tornam-se indispensáveis ao estabelecimento de correspondências entre oferta do campo e demanda da cidade no fornecimento de alimentos. Merece destaque o papel que assume a assistência técnica pública (governamental e não governamental) tanto na formação para o planejamento e a gestão de processos produtivos e elaboração de projetos para mercados institucionais quanto no estímulo e na orientação para a constituição de cooperativas (Paula et al., 2014).

O volume de recursos disponibilizados para compras da agricultura familiar pelas universidades federais tem apresentado crescimento desde a criação da modalidade $\mathrm{Cl}$ em 2012, com pico em 2016, com valor superior a $\mathrm{R} \$ 17$ milhões, influenciado, principalmente, pela atuação da Universidade Federal do Rio Grande do Sul (UFRGS), com aproximadamente 13 milhões (Tabela 2). Apesar da tendência de crescimento até 2016, ocorreram oscilações no volume de compra entre os anos. A UFRGS, por exemplo, após iniciar no PAA com chamada de quase $\mathrm{R} \$ 13$ milhões em 2016, reduziu o valor para $\mathrm{R} \$ 2,6$ milhões no ano seguinte. A Universidade Federal do Paraná (UFPR), pioneira no conjunto analisado, reduziu de $R \$ 1,7$ milhão em 2013 para pouco mais de $R \$ 413$ mil em 2015. Ademais, o volume adquirido pelo conjunto de instituições ainda é um valor absoluto baixo comparativamente às dimensões do orçamento para a alimentação das universidades brasileiras, do problema em si e do potencial do Programa. No período analisado, o número de universidades com chamadas no Programa passou de 1 em 2012 para 10 em 2019, oscilando entre as executoras - que ao longo do período totalizam 19. É pertinente destacar que em período anterior ao Decreto $n^{\circ}$ 8.473, de 22 de junho de 2015, as federais do Paraná, de Viçosa, de Santa Maria e de Pelotas lançaram chamadas públicas para aquisição de alimentos da agricultura familiar.

Os valores da Tabela 2 precisam ser relativizados pelo número de discentes de cada instituição, e, por essa razão, interessa muito mais conhecer os motivos das flutuações no lançamento de chamadas ao longo do período em cada universidade do que propriamente a identificação de valores absolutos. Ao relativizar o volume de aquisição pelo número de discentes na graduação em cada instituição (Tabela 2), destacam-se a UFRGS, a Universidade Federal de Pelotas (UFPel), a Universidade Federal do Acre (UFAC), a Universidade Federal de Santa Maria (UFSM), a Universidade Federal de Ouro Preto (UFOP) e a Universidade Federal do Piauí (UFPI). Apesar de a UFPI e a UFAC apresentarem expressivo volume de recursos destinados à agricultura familiar por aluno, os valores efetivados estão abaixo de $60 \%$.

A UFRGS destaca-se como a instituição que mais destinou recursos à compra da agricultura familiar (concentrando mais de $40 \%$ do total de $\mathrm{R} \$ 51$ milhões), sucedida pela UFPel e pela UFSM, todas localizadas no Rio Grande do Sul, estado que aparece como o principal executor do PAA e também do PNAE, fato que pode estar relacionado ao número elevado de agricultores familiares e à força de suas organizações (Baccarin et al., 2017; Grisa, 2012). Conforme anteriormente conjecturado, o fenômeno de demandas superiores no Sul pode conter, como variável explicativa, a estrutura da agricultura familiar e consequentes canais consolidados de vendas, conforme registram Siliprandi \& Cintrão (2014), quando alegam que, no caso da UFPel, a comercialização 


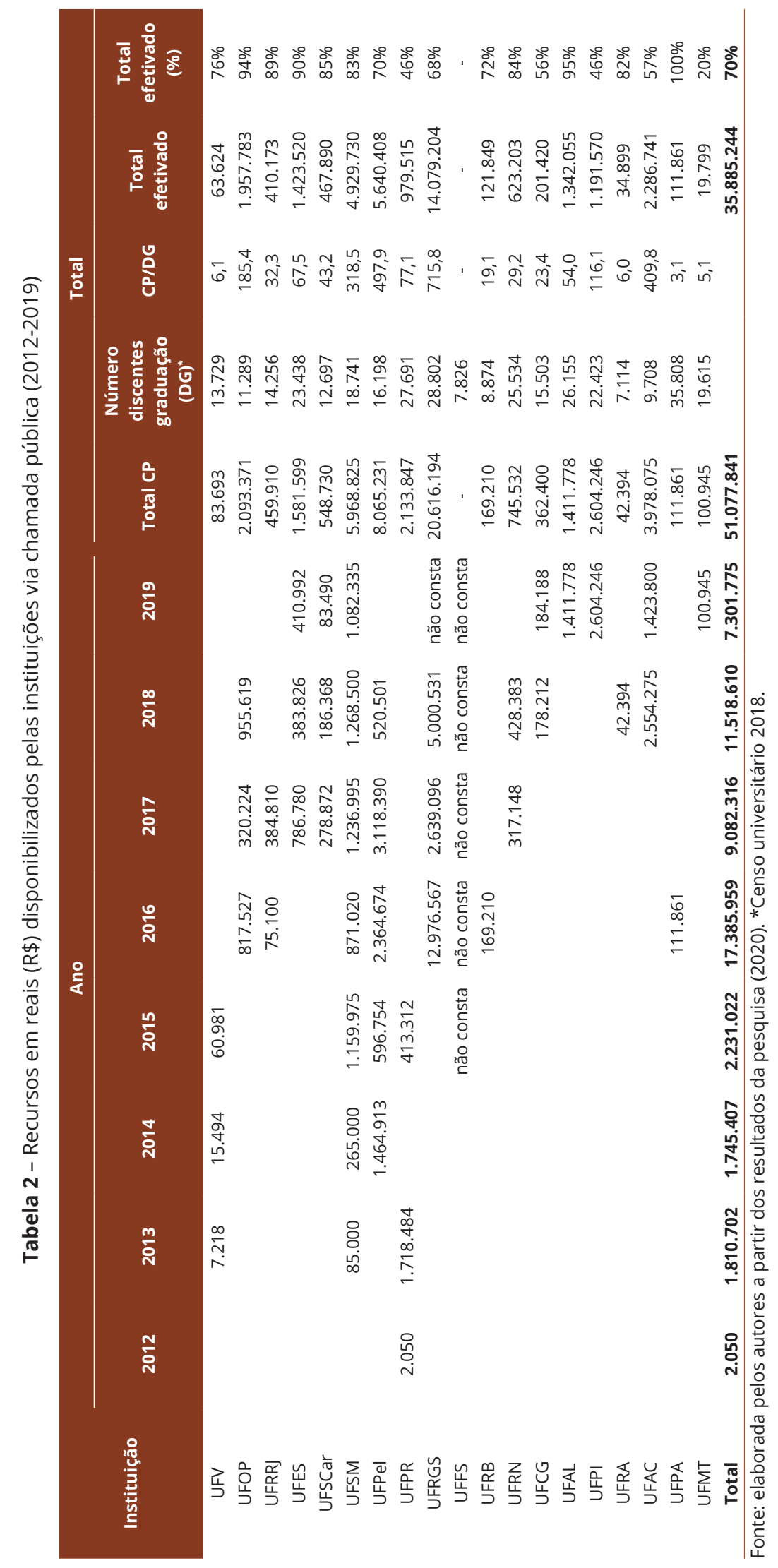


foi viabilizada por cooperativas ou por contratos de integração com agroindústrias. De outra forma, um ponto central do fenômeno reside na dimensão político-institucional, notadamente na decisão da administração central das universidades. Outro fator a ser considerado é que as áreas rurais da região Sul têm consolidada trajetória no cooperativismo da agricultura familiar.

Na região Nordeste, onde se encontram os maiores índices de insegurança alimentar e de extrema pobreza rural e, adicionalmente, a maior concentração de agricultores familiares em vulnerabilidade socioeconômica e/ou mesmo de sobrevivência (Mielitz, 2014), a execução do PAA-Cl por parte das universidades federais é frágil, e cinco instituições apenas haviam lançado chamadas no período analisado: Universidade Federal do Recôncavo da Bahia (UFRB), Universidade Federal do Rio Grande do Norte (UFRN), Universidade Federal de Campina Grande (UFCG), Universidade Federal de Alagoas (UFAL) e UFPI. Esse resultado, em contraposição aos resultados do Sul, indica que há disfuncionalidades na cobertura do PAA, as quais tendem a se aprofundar. Conforme alertaram Grando \& Ferreira (2013, p. 18), é acentuada a participação do segmento de agricultores familiares "mais consolidados", contrariando a concepção original "que deveria atender preferencialmente agricultores em situação de exclusão social".

Apesar de a compra da agricultura familiar ser obrigatória para todas as universidades a partir de 2016 (Decreto n 8.473), das 19 instituições apenas a UFSM lançou chamadas públicas em todo o período 2016-2019. Embora a UFRGS e a UFPel também tenham destaque com compras contínuas até 2018, não lançaram chamada pública em 2019. A descontinuidade de execução na UFPel pode ser explicada pela terceirização do serviço de alimentação do restaurante universitário em 2019. A UFRGS iniciou a terceirização em 2017, manteve chamada no ano seguinte, mas descontinuou em 2019. Descontinuidades ocorreram também na UFPR e na UFV, instituições pioneiras no processo de compra. Na UFV, a troca de gestão foi apontada por Salgado (2016) como um dos fatores de descontinuidade, ocasionada pela perda de informações e de capacidade de implementação. Na UFPR, tal fato se deveu a desentendimentos entre o modelo de compra adotado pela universidade a partir de 2015, fundamentado no menor preço, e a reivindicação dos agricultores, por preços abertos e adequação da universidade às suas necessidades (Giombelli, 2018). Nesse ponto, é relevante destacar que o processo de chamada pública é isento de adoção de critério de preço mínimo. Em contraposição, são adotados valores de referência locais, coletados por equipe própria da instituição interessada na compra e/ou adotados pela Companhia Nacional de Abastecimento (Conab) e órgão público do setor de agricultura e extensão rural.

Pesquisas realizadas sobre o PAA em universidades federais (Assis, 2016; Giombelli, 2018; Oliveira, 2017; Paula, 2016; Salgado, 2016; Vargas, 2017) relatam barreiras enfrentadas pelas universidades na operacionalização, com destaque para: escassez de mapeamento da produção e das condições estruturais das organizações da agricultura familiar; inexperiência da instituição; chamadas públicas que não refletem a produção local da agricultura familiar, implicando limitados alcances em abrangência e na inclusão de agricultores; fragilidades em termos de estrutura física e padronização dos produtos demandados.

É importante destacar que os valores das chamadas não necessariamente foram executados conforme mostra a última coluna da Tabela 2 . O total dos recursos das chamadas equivale a $R \$$ 51 milhões. Desse valor, $\mathrm{R} \$ 35$ milhões foram efetivamente contratados. Do total de 19 universidade, 14 contrataram percentual inferior a 90\% do que solicitaram e 36 (59\%) chamadas apresentaram itens fracassados ou atendimento parcial da demanda, o que corrobora o entendimento da inexperiência das instituições com chamadas públicas, que podem não refletir na produção local da agricultura familiar. A variedade de produtos fracassados variou desde itens in natura, como verduras, leguminosas e frutas, produtos minimamente processados, como couve picada e 
moranga descascada, a produtos ultraprocessados, como óleo de soja, refresco em pó, massa de macarrão, derivados do leite e cortes de carnes. Isso remete a possíveis problemas na adequação das chamadas públicas aos agricultores familiares e na sua eficiência enquanto instrumento de aquisição de produtos. Além da ausência de informações essenciais, que será abordada na seção seguinte, essas inconsistências podem estar relacionadas à demanda de gêneros alimentícios não produzidos pela agricultura familiar na região, como maçã nacional no Mato Grosso e limão-taiti no Rio Grande do Norte, estados que não produzem ou têm produção ínfima de tais produtos, de acordo com dados do Censo Agropecuário 2017. Também pode ser causada por pedidos fora do período de safra ou a preços não compensatórios.

A demanda pela chamada pública de produtos que não são produzidos pela agricultura familiar na região pode levar a iniciativas de atravessamento por parte de indivíduos ou agricultores familiares para atender à chamada pública. Apesar de não fazer parte das atribuições das universidades, entende-se ser necessário realizar um mapeamento da realidade produtiva da agricultura familiar antes de lançar editais de chamada pública. As universidades devem apropriar-se das realidades agrícolas locais e regionais de modo a refletir na sua demanda os produtos característicos e sazonais. Assim, o planejamento dos cardápios requer a verificação das características dos diferentes produtos, pois alguns alimentos possuem ciclo produtivo mais longo, outros são mais sensíveis às alterações climáticas (sazonalidade), interferindo no abastecimento.

O fornecimento regular no PAA exige articulação entre quem compra e quem vende de modo a instituir um processo de compra contínuo e eficaz. A interlocução entre os diferentes segmentos envolvidos não deve se restringir apenas a propósitos de planejamento, elaboração de cardápios e valorização da cultura alimentar local, mas deve também estimar efeitos das compras governamentais para a sustentabilidade ambiental e socioeconômica, ao contribuir para o desenvolvimento local a partir de circuitos curtos de produção, comercialização e consumo de alimentos. Trata-se de possibilidades de desenvolvimento endógeno. Nesse quesito, as instituições universitárias têm papel fundamental na oferta de capacitação aos agricultores e gestores a respeito da legislação, das condições para atender às normas sanitárias e da regularidade de entrega do produto, além de assumir papel para incentivar a formação e a consolidação de cooperativas e associações da agricultura familiar.

Assis (2016), Salgado (2016) e Paula (2016) relataram que o principal destino dos produtos do PAA nas universidades federais é para os restaurantes universitários, mas também atendem às creches e alunos do ensino médio nas instituições que oferecem as modalidades de ensino infantil, escolas técnicas e escolas de aplicação. A alimentação é oferecida à comunidade acadêmica, funcionários e estudantes universitários, incluindo alunos em vulnerabilidade social, em especial aqueles atendidos por ações de assistência estudantil. Em geral, são restaurantes de grande porte que demandam elevados quantitativos e diversidade de gêneros alimentícios, convencionalmente adquiridos por meio de licitação com participação de empresas especializadas não localizadas no município que abastecem e que fornecem produtos com considerável grau de processamento, armazenáveis por longo período de tempo e com reduzida necessidade de manipulação na preparação.

Ao incorporar o agricultor familiar no abastecimento de tais unidades de alimentação e nutrição, as universidades quebram o monopólio de grandes fornecedores de produtos industrializados e padronizados. A compra via chamadas públicas requer, assim, decisão política preliminar no nível da administração central e, na sequência, preparação dos responsáveis pelos processos de compras e dos técnicos de nutrição, que precisam adequar os cardápios às condições produtivas dos agricultores familiares locais/regionais e redefinir a atuação da equipe de cozinha para novas tarefas e novos tempos/jornadas de trabalho. 
Os resultados demonstram que nem sempre os produtos solicitados pelas chamadas públicas foram adquiridos pelas universidades, e, nesta pesquisa, 59\% das chamadas tiveram itens fracassados, conforme abordado anteriormente. Isso remete à necessidade de avaliar se as chamadas públicas estão sendo formuladas de forma a serem adequadas ao público e aos produtos da agricultura familiar - investigação realizada na seção seguinte.

Adequação das chamadas públicas ao público e aos produtos da agricultura familiar

Esta seção analisa as chamadas públicas utilizando como referência o modelo avaliativo apresentado na Figura 1. A Tabela 3 apresenta os dados das variáveis de desempenho relacionadas ao incentivo ao associativismo e cooperativismo, à produção agroecológica e orgânica e aos mercados local e regional. Os dados corroboram achados de pesquisas anteriores que apontam a importância da organização produtiva para o acesso às políticas públicas de $\mathrm{Cl}$ : aproximadamente $40 \%$ ( $n=26$ ) das chamadas restringiam a participação a apenas organizações formais, e a maioria das chamadas públicas possuía algum critério de priorização para cooperativas ou associações (70\%; $n=45$ ). É pertinente destacar que a exigência do fornecimento por cooperativas e associações tem o mérito tanto de estimular a organização dos agricultores para o acesso ao mercado do PAA-Cl quanto de simplificar o processo interno de gestão e controle.

Tabela 3 - Perfil dos editais de chamadas públicas de agricultores familiares nas universidades federais brasileiras, 2012-2019 $(n=64)$

\begin{tabular}{|c|c|c|}
\hline Variável & $\mathbf{n}$ & $\%$ \\
\hline \multicolumn{3}{|l|}{ Restrição à participação } \\
\hline Apenas organizações & 26 & 40 \\
\hline Organizações e agricultores individuais & 38 & 60 \\
\hline \multicolumn{3}{|l|}{ Priorização de agricultores organizados } \\
\hline Com priorização & 45 & 70 \\
\hline Sem priorização & 19 & 30 \\
\hline \multicolumn{3}{|l|}{ Priorização de produtos agroecológicos } \\
\hline Com priorização & 50 & 94 \\
\hline Sem priorização & 3 & 6 \\
\hline \multicolumn{3}{|l|}{ Critério de seleção da proposta vencedora } \\
\hline Menor preço & 33 & 52 \\
\hline Outros & 31 & 48 \\
\hline \multicolumn{3}{|l|}{ Priorização de agricultores locais } \\
\hline $\begin{array}{l}\text { Agricultores do município } \\
\text { Outros critérios }\end{array}$ & 33 & 52 \\
\hline
\end{tabular}

Cooperativas e associações locais tendem a gerar relações de desconfiança entre técnicos e gestores públicos em virtude do papel institucional que passam a exercer, não apenas no tocante ao desenvolvimento rural, mas também no fornecimento de atividades de apoio e serviços (Cremonese \& Schallenberger, 2005; Mohamed, 2004). Estudos têm evidenciado o importante papel das cooperativas e associações na organização dos agricultores familiares, na competitividade e no acesso a mercados, especialmente os governamentais (Aref, 2011; Ribeiro et al., 2013; Vogt \& Souza, 2009), viabilizando a aquisição coletiva de insumos e a contratação de assistência técnica mediante custos e preços acessíveis (Conceição Júnior \& Brito, 2013). O cooperativismo e o associativismo institucionalizam um campo social, político e econômico por meio do qual os agricultores podem fomentar a produção e executar ações de interesse coletivo em mercados locais e regionais, preliminarmente, e, adiante, nacionais e globais (Pires, 2010). O fortalecimento de organizações econômicas, por sua vez, estimula 
a inclusão produtiva dos agricultores familiares, especialmente daqueles que necessitam de apoio para superar situações de pobreza e de extrema pobreza.

$\mathrm{A} \mathrm{Cl}$ tem possibilitado à agricultura familiar superar um dos principais desafios, conforme apontam Campos \& Bianchini (2014), que é atender diretamente, e em volume viável economicamente, às demandas de mercados exigentes que vão além do local. O fornecimento de elevados volumes nas grandes cidades, por exemplo, quer em valor, quer em quantidade de produtos, é desafiador por si só, pois necessita de expressiva eficiência e qualificada organização dos agricultores familiares e mesmo da constituição de redes, uma vez que as metrópoles (onde se encontram sediadas as maiores universidades) tendem a ter área rural insignificante, demandando produtos de outros municípios (Baccarin et al., 2017; Mielitz, 2014). Entretanto, Baccarin et al. (2017) alertam para o fato de cooperativas de agricultores familiares, de maior porte, direcionarem esforços ao fornecimento de alimentos a grandes cidades, optando por contratos vultosos, inclusive em virtude de capacidade de processamento que passam a possuir. Tais organizações, por vezes, passam a atuar como meros intermediadores na comercialização dos produtos, não repassando aos sócios os devidos retornos obtidos nos mercados governamentais e até criando estruturas e procedimentos que dificultam a relação sócio/cooperativa. A assistência técnica pública (governamental e não governamental) deve, nesse ponto, assumir o papel na qualificação do ato associativo para a prática do cooperativismo autêntico, ampliando a prestação de serviços para além da gestão de processos produtivos e da elaboração de projetos para mercados institucionais, ou puro incentivo à constituição de cooperativas, conforme defendem Paula et al. (2014).

A legislação da modalidade $\mathrm{Cl}$ estabelece, dentro dos critérios de priorização, a produção orgânica e agroecológica. Constatou-se que $94 \%(n=50)$ das chamadas públicas inseriram tal variável como critério de desempate (Tabela 3), indicando interesse das universidades por compras de alimentos saudáveis e produzidos de forma sustentável. O conteúdo das chamadas, por sua vez, evidencia que apenas a UFPel demandou especificamente alimentos de base agroecológica e orgânica. A valorização de produtos agroecológicos é necessária por contribuir para o desenvolvimento sustentável e promover a alimentação saudável (Campos \& Bianchini, 2014), além de favorecer a agrobiodiversidade e a sociobiodiversidade, aprofundando intercâmbios entre processos e organizações sociais que reúnem saberes e sabores dos distintos povos que compõem a brasilidade (Porto et al., 2014). Por essa razão, pesquisas (Grisa et al., 2011; Sambuichi et al., 2014; Schmitt \& Grisa, 2013; Triches \& Grisa, 2015) têm referenciado o estímulo do PAA à transição agroecológica, inclusive pelo fato de possibilitar aumento de até $30 \%$ no preço final de venda de produtos orgânicos ou agroecológicos. Tal viés de pesquisa encontra suporte no modelo lógico da política (Salgado, 2020), que estabelece, entre as finalidades do PAA, a promoção e a valorização da biodiversidade e a produção orgânica e agroecológica de alimentos, além do incentivo a hábitos alimentares saudáveis em níveis local e regional. Esse fato indica que as compras ainda não incorporaram indicadores de sustentabilidade, valorizando a aquisição de produtos orgânicos, agroecológicos e da sociobiodiversidade. É importante enfatizar a necessidade da inclusão de estratégias específicas para amplificar a produção e a aquisição da produção dos sistemas agrícolas sustentáveis, o que continua sendo um desafio para o Programa.

Para Mielitz (2014), a principal barreira à expansão da produção agrícola orgânica tem sido o desconhecimento por parte dos agricultores dessa possibilidade e de seu diferencial positivo de preços, além da falta de orientação técnica que possibilite a produção e assegure sua qualidade. Na maioria dos casos, os produtos fornecidos ao PAA são livres de pesticidas, mas não são vendidos como orgânicos (Siliprandi \& Cintrão, 2011) por falta de informação ou por dificuldades burocráticas no processo de certificação. Grisa et al. (2011) ressaltam que 
a principal dificuldade de inserção desses produtos no PAA é a garantia de instrumentos de avaliação de conformidade da qualidade orgânica que sejam flexíveis e adaptados à realidade das diferentes regiões brasileiras. Em virtude dessas limitações, muitos produtos agroecológicos ou orgânicos são comercializados ao Programa sem o acréscimo de 30\% nos preços de referência.

No que diz respeito aos tipos de produtos contemplados nas chamadas, é nítido o significativo incremento ao longo dos anos, tanto em quantidade quanto em variedade. Considerável gama de produtos é demandada, principalmente frutas, hortaliças, leguminosas, cereais, tubérculos, raízes, farinhas, açúcares, doces, leite e derivados, carnes e ovos. Na presente pesquisa, podese afirmar que houve a procura por alimentos diversificados e sugere-se alto valor nutricional pelas universidades, visto a grande variedade dos gêneros alimentícios encontrados e também o alto percentual de produtos in natura e minimamente processados, como frutas e hortaliças. Há demandas de produtos da sociobiodiversidade das regiões brasileiras, como maxixe e feijão-de-corda no Nordeste, jambu e peixes amazônicos no Norte. A compra de gêneros alimentícios característicos de cada região, de qualidade nutricional, é um dos méritos do PAA, por permitir melhorias na condição nutricional da população atendida ao mesmo tempo que valoriza hábitos e cultura locais de alimentação.

A partir do fornecimento de produtos em variedade, diversidade e qualidade nutricional, somado à inserção de alimentos orgânicos e agroecológicos, o Programa pode se tornar aliado das políticas públicas de educação alimentar, tornando-o um vetor de acesso a alimentos saudáveis nas universidades federais. Além do ganho nutricional, possibilita a valorização da culinária local e o conhecimento de condições socioeconômicas, recuperando tradições alimentares da cultura regional. Ao induzir a diversificação produtiva, o Programa também tende a mitigar a vulnerabilidade social dos produtores. Aqui são promovidos mais fortemente dois objetivos específicos do Programa: "acesso à alimentação adequada e saudável" e "incentivo ao consumo e valorização dos alimentos da agricultura familiar".

A diversidade de produtos demandados, especialmente daqueles passíveis de serem produzidos nas hortas e quintais, cria mercados para produtos predominantemente utilizados para o autoconsumo, que têm experimentado redução de produção nas regiões com predomínio da venda de produtos comerciais ou com trabalho assalariado. Dessa forma, o PAA contribui para uma alimentação mais diversa, natural e menos dependente dos produtos agroindustrializados. O suporte do PAA ao processo de diversificação é uma importante estratégia de fortalecimento do sistema de produção de base familiar, dado que promove segurança em termos de renda e, adicionalmente, contribui para a conservação do meio ambiente, estratégia fundamental para garantir o desenvolvimento e a sustentabilidade econômica para os agricultores familiares (Sambuichi et al., 2014).

Nas chamadas das universidades, é expressiva a presença de produtos beneficiados, tais como polpas de fruta, doces, conservas, panificados, bolos, queijos, iogurtes, produtos minimamente processados e carnes (este item é em menor volume). A maioria dos produtos processados demandados refletem cultura alimentar e potencialidades de cada região, como as cucas e as massas com trigo na região Sul, o pó de café na Zona da Mata mineira, a farinha de mandioca nas regiões Norte e Nordeste, as polpas de frutas típicas, o leite de coco e as gomas de mandioca (tapioca) no Nordeste e o tucupi e o caruru no Norte. Além da agregação de valor, a demanda contínua tende a estimular a estruturação de pequenas unidades de beneficiamento ou a melhoria nas condições daquelas já existentes, visando atender às condições de qualidade exigidas. Desta forma, o Programa pode contribuir para uma melhor estruturação da produção e do processamento e adequação às exigências sanitárias, permitindo às famílias acessarem outros mercados, que passam a absorver o excedente chancelado pelo padrão de qualidade das universidades, despertando atenção dos consumidores. Entretanto, 
deve-se ponderar que a venda de produtos processados pela agricultura familiar ainda enfrenta limitações, relacionadas às barreiras sanitárias e tecnológicas, especialmente os produtos de origem animal, que devem obedecer rigorosos requisitos sanitários de serviços municipais, estaduais e federais (Baccarin et al., 2017; Chmielewska et al., 2010).

É relevante destacar que 33 (52\%) chamadas públicas de 9 (47\%) universidades adotaram o critério de menor preço na seleção das propostas (Tabela 3). Tal medida se contrapõe aos objetivos do PAA e não está prevista em suas normas legais. Conforme observa Baccarin et al. (2017), o objetivo da chamada pública é garantir preços justos, e, assim, o valor apresentado nas propostas não pode se tornar objeto de disputa entre agricultores familiares. Tal parâmetro de mercado concorrencial pode resultar em riscos à saúde dos consumidores, uma vez que o critério de produção orgânica e agroecológica não tem sido pautado na quase totalidade das chamadas, e, desse modo, produtos com menor custo e preço final inferior, alcançados por meio de sistemas de produção que utilizam produtos químicos e agrotóxicos, passam a ser adquiridos em detrimento de produtos saudáveis, cultivados em bases sustentáveis.

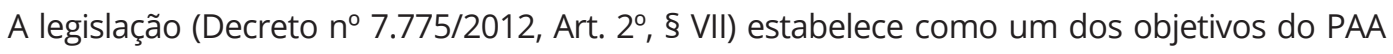
fortalecer circuitos locais e regionais e redes de comercialização, e tal critério aparece em 33 compras públicas (52\%), indicando que a política privilegia a movimentação local dos recursos públicos recebidos, outro objetivo da política. Para Baccarin et al. (2017), esses circuitos contribuem para incrementar o consumo de alimentos in natura- um dos itens previstos no referido decreto (Art. $5^{\circ}$ ). É oportuno destacar que os circuitos curtos têm potencial para promover e valorizar a biodiversidade e a produção orgânica e agroecológica de alimentos, incentivando hábitos alimentares saudáveis em nível local e regional, o que igualmente apregoa o já citado decreto (Art. $2^{\circ}, \S$ VIII).

Predominam nas chamadas (Tabela 4) os produtos de origem vegetal, na forma in natura, em detrimento dos de origem animal, indicando alinhamento às condições gerais do agricultor familiar no Brasil e de suas organizações. Resultado semelhante foi encontrado por Baccarin et al. (2017), Ferigollo et al. (2017) e Triches \& Silvestri (2018) no PNAE. Tal constatação reflete adequação das chamadas ao guia alimentar brasileiro (Brasil, 2014) e indica que a legislação está permitindo às universidades adquirir e fornecer alimentos mais nutritivos e saudáveis, de procedência conhecida e, portanto, mais confiáveis. A opção por produtos locais, in natura, colabora tanto para a formação de hábitos alimentares afinados à vocação agrícola e cultura alimentar local quanto para a inclusão econômica e social de agricultores com limitada capacidade de investimento, apontando para a eficácia do Programa e o atendimento de seus objetivos. Por outro lado, a presença expressiva de produtos de origem animal (57\%) sugere que o segmento da agricultura familiar está se adequando à legislação sanitária e às questões de transformação industrial prévia dos produtos de origem animal, normalmente realizada em unidades de grande porte.

Com relação aos aspectos logísticos, a solicitação da entrega em uma única unidade de recebimento (por exemplo, no restaurante universitário) foi prevalente. A maioria das entregas é centralizada, e isso tende a favorecer o agricultor familiar, pois ele consegue cumprir suas responsabilidades de entrega, planejar as questões logísticas e ainda atender à distribuição dos alimentos das universidades e campi.

Em relação à periodicidade das entregas, a semanal foi a mais encontrada. As unidades de abastecimento alimentar das universidades, geralmente, não possuem grande capacidade de armazenagem, sobretudo de produtos perecíveis, como os hortifrutigranjeiros (Assis, 2016; Salgado, 2016; Vargas, 2017), o que exige fluxo de produtos com maior frequência. Por isso, constatou-se tendência ao estabelecimento da frequência de entrega de acordo com o tipo de produto: produtos perecíveis tinham entrega semanal; produtos não perecíveis ou semiperecíveis tinham entrega quinzenal ou mensal. Baccarin et al. (2017) alertam que a entrega mais de uma 
vez por semana se torna onerosa para os agricultores familiares dado o custo com logística, o que pode inviabilizar a participação nas chamadas, caso não ocorra ganho de escala com outros produtos ou mercados. Já a entrega semanal é indicada como compatível com as condições da agricultura familiar e com a compra de vegetais in natura. Em qualquer situação, o agricultor familiar reduz os custos de entrega quando cooperado ou associado.

Informação sobre a periodicidade de entrega não constava em aproximadamente metade das chamadas públicas ou estava imprecisa. Todavia, essa informação é de extrema importância tanto para o agricultor avaliar a relação custo-benefício (em relação ao custo de logística) quanto para planejar o calendário agrícola considerando os períodos de entrega requeridos pela instituição compradora. Assim, a definição da periodicidade de entrega deve levar em conta não só o calendário universitário, mas também o calendário agrícola. A necessidade de harmonização entre calendários específicos exige que, desde a origem, a chamada pública tenha diálogos das instituições com o segmento da agricultura familiar. Por outro lado, os agricultores familiares, a partir da garantia de fornecimento e do cronograma de entrega, devem repensar e reprogramar suas atividades agropecuárias ao longo do ano para atender às necessidades das instituições.

Quanto à indicação do preço dos produtos, praticamente todas as chamadas públicas continham essa informação, cuja presença garante que os preços não sejam maiores que os praticados no atacado e no varejo alimentício, não onerando as compras públicas. Além disso, garantem melhor remuneração para os agricultores familiares do que a obtida em canais de comercialização convencionais. Quando comparado ao resultado da pesquisa de Ferigollo et al. (2017), no PNAE em âmbito municipal, em que aproximadamente um terço das chamadas analisadas não indicava preço de referência, o desempenho das universidades é bem mais favorável, considerando que apenas 5\% (3) omitiram tal informação.

Tabela 4 - Perfil dos editais de chamadas públicas de agricultores familiares nas universidades federais brasileiras, 2012-2019 $(n=58)$

\begin{tabular}{lcc}
\multicolumn{1}{c}{ Variável } & $\mathbf{n}$ & $\%$ \\
Origem dos alimentos & 33 & \\
$\quad$ Animal & 51 & 56,9 \\
$\quad$ Vegetal & & 87,9 \\
Grau de processamento dos alimentos & 667 & 68,7 \\
In natura & 94 & 8,5 \\
Mínimo & 136 & 10,8 \\
$\quad$ Médio & 139 & 11,9 \\
$\quad$ Alto & 11 & \\
Periodicidade de entrega & 16 & 15,1 \\
2 a 5 vezes/semana & 11 & 21,9 \\
Semanal & 35 & 15,1 \\
1 a 3 vezes/mês & & 47,9 \\
$\quad$ Não consta informação & 19 & 67,9 \\
Unidades de recebimento (UR) & 6 & 21,4 \\
Centralizada (1 a 5 UR) & 3 & 10,7 \\
Descentralizada (> 5) & & \\
$\quad$ Não consta informação & 55 & 94,8 \\
Contém os preços dos produtos & 3 & 5,2 \\
Sim & Não consta informação &
\end{tabular}

Fonte: elaborada pelos autores a partir dos resultados da pesquisa (2018). 
Os dados aqui apresentados indicam que o instrumento de chamada pública ainda precisa de ajustes e que nem todas as universidades têm conseguido elaborá-lo, tornando-o ineficiente em sua finalidade. Informação de preços de referência e indicação de local de entrega centralizado influenciam positivamente o sucesso das chamadas, e considera-se que nesses quesitos as universidades têm incentivado a agricultura familiar, com consequente promoção de efeitos benéficos e continuados em sua renda e, por conseguinte, no desenvolvimento local. Essas informações, somadas à periodicidade de entrega, são imprescindíveis para orientar a decisão dos agricultores familiares no tocante à decisão de apresentação de proposta para comercialização de produtos, mediante apreciação da relação custo-benefício, de variáveis como frequência, quantidades requisitadas, preços e locais de entrega. Tais carências podem prejudicar tanto a execução por parte das entidades demandantes quanto os agricultores, que ficam desamparados na avaliação acerca da viabilidade de participação e entrega de proposta, tornando essa política menos efetiva para o alcance dos seus objetivos. Por essa razão, a análise de fracassos em chamada pública de aquisição de alimentos da agricultura familiar requer, antes de tudo, averiguação da precisão do próprio conteúdo - e essa constatação é útil a todas as situações de compras do PAA e do PNAE.

\section{CONSIDERAÇÕES FINAIS}

O exame da $\mathrm{Cl}$ de produtos da agricultura familiar, na execução do PAA pelas universidades federais, indica restrita adesão, considerando que, de 63 unidades, apenas 30\% haviam cumprido, em algum grau, a determinação do Decreto $n^{\circ} 7.775 / 2012$. Ademais, o fato de haver chamada pública divulgada não implica, necessariamente, que as aquisições sejam efetivadas nos itens, quantitativos e valores projetados. A análise empreendida indica que a maioria das universidades que compram produtos da agricultura familiar põe neles apenas algumas de suas necessidades cobertas e não necessariamente de forma regular. A avaliação empreendida indicou pequena e desigual execução do PAA-CI no abastecimento dos restaurantes universitários, contemplando um pequeno número de agricultores familiares no país. Expandir o PAA-Cl em termos de números de universidades federais compradoras, número de agricultores e organizações beneficiadas e recursos disponibilizados é um dos primeiros desafios a elencar.

A pesquisa aqui narrada aponta para a necessidade de diálogo das universidades com o segmento da agricultura familiar no momento da elaboração das chamadas de modo a ponderar elementos como itens passíveis de entrega pela agricultura familiar local/regional, sazonalidade, preços de referência, regime e local de entrega e demais requisitos úteis à tomada de decisão dos agricultores no exame das possibilidades de participação nos certames e de custo-benefício. Neste sentido, a efetividade da implementação do PAA-CI nas universidades federais e demais instituições federais depende, em grande medida, da coordenação de esforço entre gestores, lideranças das organizações e movimentos sociais para garantir um salto na oferta de gêneros alimentícios para o abastecimento em quantidade e qualidade das universidades federais. Além disso, é preciso que os gestores de compras públicas reconheçam as compras da agricultura familiar como parte de uma estratégia de contribuição para a superação de indicadores de pobreza e promoção de desenvolvimento local e territorial sustentáveis.

A drástica redução no volume de recursos disponibilizados para o PAA a partir de 2013 pelo Governo Federal para as ações de combate à fome e acesso à alimentação, concentradas especialmente na modalidade Compra com Doação Simultânea, demonstra uma tendência já evidenciada por Campos \& Bianchini (2014): os serviços e equipamentos públicos, como as universidades federais, forças de defesa, hospitais e presídios, tendem a ser os principais 
fornecedores da população carente ou daquela que estuda, recupera-se ou se trata em equipamentos públicos, tornando-se um dos principais mercados para os produtos da agricultura familiar. Entretanto, há de se destacar que, para que esses benefícios sejam alcançados, é necessário que a política caminhe para favorecer agricultores com baixo capital social e regiões mais pobres do país. Os dados aqui levantados, ao contrário, indicam que o Programa tem tido melhor desempenho em regiões em que a agricultura familiar possui alto capital social e já se encontram integrados a mercados por meio de cooperativas, apontando uma limitação evidenciada no PAA como um todo.

Há de se destacar que a instituição da modalidade $\mathrm{Cl}$ e o posterior decreto obrigando os órgãos públicos a comprar $30 \%$ da demanda alimentícia da agricultura familiar tendem a institucionalizar o PAA, garantindo-lhe a função de política permanente de Estado em articulação com outras iniciativas e/ou programas, como reforma agrária e alimentação escolar. Por outro lado, o número restrito de universidades comprando da agricultura familiar e a descontinuidade em algumas instituições podem ser reflexo das limitações impostas pela publicação do Decreto $n^{\circ}$ $9.262 / 2018$, que extingue cargos da carreira de técnico administrativo das instituições federais de ensino superior, afetando cargos operacionais (como cozinheiro e auxiliar de cozinha) dos restaurantes universitários e comprometendo o fornecimento de alimentação. Percebeu-se uma tendência à terceirização dos restaurantes universitários como alternativa para enfrentar esse desafio, por exemplo, nos casos da UFV, UFOP e UFPel. Ao optar pela terceirização, as universidades escolhem continuar comprando produtos processados por meio de processo licitatório e de um número restrito de empresas, predominantemente localizadas fora do município sede da instituição, visto que esse tipo de administração privilegia o menor custo.

Apesar das fragilidades apontadas nesta pesquisa, é preciso levar em conta que a legislação é relativamente nova, mesmo que as compras já sejam permitidas desde 2012. A obrigatoriedade, todavia, só passou a ser aplicada a partir de 2016, o que exige período de aprendizagem, tanto dos gestores universitários quanto dos agricultores familiares. Outra explicação é o posicionamento contrário das instituições à legislação de compras, somado à inexistência de mecanismos punitivos às universidades que não cumprem exigências do Programa.

A combinação do PAA-Cl com outros programas, como o PNAE, feiras livres, crédito agrícola e assistência técnica pública, tem potencial para induzir o desenvolvimento local pelo estímulo à produção diversificada, pelo incremento no número de agricultores e no volume de recursos disponibilizados para a agricultura familiar e pelo fomento à criação e ao fortalecimento de cooperativas e associações. Da mesma forma, seria importante o reforço da participação de órgãos de Ater e das próprias universidades, atuando conjuntamente com nutricionistas no planejamento dos cardápios e na orientação aos agricultores familiares, de forma a adequar o calendário de compra ao do ciclo de produção.

É importante ressaltar que nem todos os produtos demandados nas chamadas públicas podem ter sido realmente comprados por causa da sazonalidade, prejuízos decorrentes de secas, chuvas e frio intenso, assim como por desistência de entrega por alguns agricultores ou das instituições demandantes.

Há lacunas a serem preenchidas pelas universidades, pois um número elevado de chamadas públicas não determinava a periodicidade e os locais de entrega. Ademais, insuficiências no conhecimento sobre o funcionamento do instrumento da chamada pública e do PAA, especificamente, conduzem equipes de burocratas a imprecisões na definição de critérios de elegibilidade e dificultam associações entre a execução do PAA-Cl e outras políticas dirigidas ao fortalecimento da agricultura familiar. Nesse quesito, reside uma possibilidade de pesquisa, qual seja, a sistematização de experiências de atuação de burocratas de nível de rua (Lipsky, 
2019), responsáveis pela elaboração e execução das chamadas nas universidades. Afinal, a obrigatoriedade de compras institucionais da agricultura familiar em, no mínimo 30\%, no âmbito do PAA data de 2016; portanto, é factível assumir que os burocratas das universidades, responsáveis por elaborarem e executarem a medida, tenham conhecimentos limitados acerca do segmento em que precisam atuar.

Os resultados obtidos demonstraram que tanto a elaboração de cardápios quanto a elaboração de chamadas afetam diretamente a decisão de execução pela agricultura familiar. Ratifica-se, assim, a necessidade de diálogos para a seleção dos itens e levantamento de possibilidades de oferta para que se estabeleça uma relação comprometida não apenas com o gesto automático de cumprir a legislação, mas de construir um mercado institucional para os produtos da agricultura familiar. Além disso, lacunas e imprecisões, afetando negativamente a qualidade das informações nas chamadas, são elementos a considerar em avaliações futuras de desempenho de compras governamentais da agricultura familiar.

\section{Referências}

Anjos, F. S., \& Becker, C. (2014). Agricultura familair e mercados institucionais: o desenvolvimento como liberdade. Revista Economica do Nordeste, 45, 92-101.

Aref, F. (2011). Agricultural cooperatives for agricultural development in Iran. Life Science Journal, 8(1), 82-85.

Assis, S. C. R. (2016). Implementação do Programa de Aquisição de Alimentos, modalidade compra institucional, na Universidade Federal de Viçosa, Minas Gerais e situação de (in) segurança alimentar e nutricional dos agricultores familiares beneficiários fornecedores (Dissertação de mestrado). Universidade Federal de Viçosa.

Baccarin, J. G., Triches, R. M., Teo, C. R. P. A., \& Silva, D. B. P. (2017). Indicadores de Avaliação das Compras da Agricultura Familiar para Alimentação Escolar no Paraná, Santa Catarina e São Paulo. Revista de Economia e Sociologia Rural, 55(1), 103-122.

Brasil. Ministério da Saúde. (2014). Guia alimentar para a população brasileira (2. ed.). Ministério da Saúde.

Brasil. Ministério do Desenvolvimento Social. (2018). Programa de aquisição de alimentos. Recuperado em 27 de janeiro de 2021, de http://mds.gov.br/assuntos/seguranca-alimentar/ programa-de-aquisicao-de-alimentos-paa

Campos, A., \& Bianchini, V. (2014). Agricultura Familiar passa a ser prioridade de Estado. In M. E. Del Grossi \& D. R. Kroeff (Eds.), PAA: 10 anos de aquisição de alimentos (280 p.). MDS.

Chmielewska, D., Souza, D., \& Lourete, A. A. (2010). O Programa de Aquisição de Alimentos da Agricultura Familiar (Paa) e as práticas dos agricultores participantes orientadas ao mercado: estudo de caso no estado de Sergipe (Texto Para Discussão, No. 1510, pp. 16891699). IPEA. https://doi.org/10.1017/CBO9781107415324.004.

Companhia Nacional de Abastecimento - CONAB. (2014). Programa de Aquisição de Alimentos - PAA - resultados das ações da Conab 2013. Brasília.

Conceição Júnior, V., \& Brito, I. P. F. S. (2013). Fortalecimento da agricultura familiar como instrumento para o desenvolvimento rural do Território de Vitória da Conquista - Bahia. Revista Extensão \& Cidadania, 1(1), 131-141.

Costa, F., \& Castanhar, J. (2005). Avaliação de programas públicos: desafios conceituais e metodológicos. Revista de Administração Pública, 37(22), 969-992. 
Cremonese, C., \& Schallenberger, E. (2005). Tempo da Ciência. Tempo da Ciência, 23(12), 49-63.

Dias, T. F., Nunes, E. M., Torres, F. de L., \& Torres, A. C. M. (2013). O programa de aquisição de alimentos da agricultura familiar (PAA) como estratégia de inserção socioeconômica: o caso do Território da Cidadania Sertão do Apodi (RN). Revista Brasileira de Gestao e Desenvolvimento Regional, 9(3), 100-129.

Ferigollo, D., Kirsten, V. R., Heckler, D., Figueiredo, O. A. T., Perez-Cassarino, J., \& Triches, R. M. (2017). Aquisição de produtos da agricultura familiar para alimentação escolar em municípios do Rio Grande do Sul. Revista de Saude Publica, 51(6), 1-10.

Food and Agriculture Organization - FAO. (2020). The state of food security and nutrition in the world 2020. Rome: FAO.

Frey, K. (2000). Políticas públicas: um debate conceitual e reflexões referentes à prática da análise de políticas públicas no Brasil. Planejamento e Políticas Públicas, (21).

Giombelli, G. P. (2018). Trânsição sustentável das compras públicas de alimentos: o caso dos restaurantes das universidades federais no estado do Paraná (Dissertação de mestrado). Universidade Federal da Fronteira Sul.

Grando, M. Z., \& Ferreira, G. S. (2013). O Programa de Aquisição de Alimentos (PAA) e sua relação com o Rio Grande do Sul (Texto Para Discussão, No. 113). FEE.

Grisa, C. (2012). Políticas públicas para a Agricultura Familiar no Brasil: produção e institucionalização das ideias (Tese de doutorado). Universidade Federal Rural do Rio de Janeiro.

Grisa, C., Schmitt, C. J., Mattei, L. F., Maluf, R. S., \& Leite, S. P. (2011). Contribuições do Programa de Aquisição de Alimentos à segurança alimentar e nutricional e à criação de mercados para a agricultura familiar. Revista Agriculturas, 8(3), 34-41.

Guilhoto, J. J. M., Azzoni, C. R., Silveira, F. G., Ichihara, S. M., Diniz, B. P. C., \& Moreira, G. R. C. (2007). PIB da Agricultura Familiar. NEAD.

Howlett, M., Perl, A., \& Ramesh, M. (2012). Política pública: seus ciclos e subsistemas: uma abordagem integral. Elsevier.

Januzzi, P. M. (2011). Avaliação de programas sociais no Brasil: repensando práticas e metodologias das pesquisas avaliativas (Planejamento e Políticas Públicas, No. 36).

Kaminski, R. da S., Sambuichi, R. H. R., Moura, I. F., \& Januario, E. S. (2018). Desafios metodológicos para a avaliação de programas governamentais: o caso do Programa de Aquisição de Alimentos (Boletim Regional, Urbano e Ambiental, No. 18).

Lipsky, M. (2019). Burocracia de nível de rua: dilemas do indivíduo nos serviços públicos. ENAP.

Mielitz, C. (2014). Dez anos de PAA e a Constituição de uma Estratégia Nacional de Segurança Alimentar. In M. E. Del Grossi \& D. R. Kroeff (Eds.), PAA: 10 anos de aquisição de alimentos (p. 280). MDS.

Mohamed, F. A. (2004). Role of agricultural cooperatives in agricultural development: the case of Menoufiya Governorate, Egypt(Tese de doutorado). Universidade de Bonn, Bonn, Alemanha.

O'Toole Junior, L. J. (2010). Relações interorganizacionais no processo de implementação. In B. Guy Peters \&J. Pierre (Eds.), Administração pública: coletânea. Unesp.

Oliveira, L. D. M. (2017). Avaliação do processo de implantação do programa de aquisição de alimentos na modalidade compra institucional na Universidade Federal do Rio Grande do Norte (Dissertação de mestrado). Universidade Federal do Rio Grande do Norte. 
Paula, M. M., Kamimura, Q. P., \& Silva, J. L. G. (2014). Mercados institucionais na agricultura familiar: dificuldades e desafios. Revista de Política Agrícola, 23(1).

Paula, N. F. (2016). Colhendo os frutos: dificuldades e conquistas da modalidade do paa compra-institucional em uma universidade pública (Dissertação de mestrado). Universidade Federal do Paraná.

Peraci, A. S., \& Bittencourt, G. A. (2010). A agricultura familiar e os programas de garantia de preços no Brasil: o Programa de Aquisição de Alimentos (PAA). In J. L. G. Silva, M. E. Del Grossi \& C. G. França (Eds.), Fome Zero: a experiência brasileira (pp. 191-222). Ministério do Desenvolvimento Agrário.

Pires, M. L. L. e S. (2010). Extensão rural e cooperativismo: o que há de novo nessa relação? Jornadas Nacionales de Extensión Rural, 15, 6-8.

Porto, S. I., Soares, E. S., Soares, J. F., Cruz, K. C. M. S., Viegas, G. L., \& Viana, C. (2014). Programa de Aquisição de Alimentos (PAA): dez anos de uma política pública múltipla e inovadora. In M. E. Del Grossi \& D. R. Kroeff (Eds.), PAA: 10 anos de Aquisição de Alimentos (p. 280). MDS.

Ribeiro, K. A., Nascimento, D. C., \& Silva, J. F. B. (2013). Cooperativismo agropecuário e suas contribuições para o empoderamento dos agricultores familiares no submédio São Francisco: o caso da associação de produtores rurais do núcleo VI - Petrolina/PE. Teoria e Evidência Econômica, 19(40), 77-101.

Salgado, R. J. S. F. (2016). Implementação do Programa de Aquisição de Alimentos (PAA): a trajetória de operacionalização do PAA Institucional na Universidade Federal de Viçosa-MG (Dissertação de mestrado). Universidade Federal de Viçosa.

Salgado, R. J. S. F. (2020). Análise expandida da atuação dos burocratas de nível de rua na implementação do Programa de Aquisição de Alimentos em universidades federais (Tese de doutorado). Universidade Federal do Rio Grande do Norte.

Salgado, R. J., Souza, W. J., Ferreira, M. A. M., \& Santos, L. F. (2020). A natureza teórico-epistemológica das publicações brasileiras no Programa de Aquisição de Alimentos (PAA). Brazilian Journal of Development, 6(3), 9998-10025.

Sambuichi, R. H. R., Galindo, E. P., de Oliveira, M. A. C., \& de Moura, A. M. M. (2014). Compras públicas sustentáveis e agricultura familiar: a experiência do Programa de Aquisição de Alimentos (PAA) e do Programa Nacional de Alimentação Escolar (PNAE). In R. H. R. Sambuichi, A. P. M. Silva, M. A. C. Oliveira \& M. Savian (Eds.), Políticas agroambientais e sustentabilidade: desafios, oportunidades e lições aprendidas (273p.). Ipea.

Sambuichi, R. H. R., Kaminsk, R., Perin, G., de Moura, I. F., Januário, E. S., Mendonça, D. B., \& de Almeida, A. F. C. (2019). Programa de Aquisição de Alimentos e segurança alimentar: modelo lógico, resultados e desafios de uma política pública voltada ao fortalecimento da agricultura familiar (Texto para Discussão). Instituto de Pesquisa Econômica Aplicada.

Saraiva, E. B., Silva, A. P. F., Sousa, A. A., Cerqueira, G. F., Chagas, C. M. S., \& Toral, N. (2013). Panorama da compra de alimentos da agricultura familiar para o Programa Nacional de Alimentação Escolar. Ciencia \& Saude Coletiva, 18(4), 927-935.

Savaya, R., \& Waysman, M. (2005). The logic model. Administration in Social Work, 29(2), 85-103.

Schmitt, C. J., \& Grisa, C. (2013). Agroecologia, mercados e políticas públicas: uma análise a partir dos instrumentos de ação governamental. In P. Niederle, L. Almeida \& F. Vezzani (Eds.), Agroecologia: práticas, mercados e políticas para uma nova agricultura. Kayrós. 
Schneider, S., Cruz, F. T., \& Matte, A. (2016). Estratégias alimentares e de abastecimento: desafios e oportunidades para as cidades e para o meio rural. In F. T. Cruz, A. Matte \& S. Schneider (Eds.), Produção, consumo e abastecimento de alimentos: desafios e novas estratégias (1. ed., 324 p.). Editora da UFRGS.

Secchi, L. (2013). Políticas públicas: conceitos, esquemas de análise, casos práticos. Cengage Learning.

Siliprandi, E., \& Cintrão, R. (2011). As mulheres agricultoras no Programa de Aquisição de Alimentos (PAA). Segurança Alimentar e Nutricional, 18(2), 13.

Siliprandi, E., \& Cintrão, R. (2014). As mulheres rurais e a diversidade de produtos no Programa de Aquisição de Alimentos. In M. E. Del Grossi \& D. R. Kroeff(Eds.), PAA: 10 anos de Aquisição de Alimentos (p. 280). MDS.

Triches, R. M., \& Grisa, C. (2015). Entre mudanças e conservadorismos: uma análise dos programas de aquisição de alimentos (PAA e PNAE) a partir da retórica da intransigência. Revista NERA, 18(26), 10-27.

Triches, R. M., \& Schneider, S. (2010). Alimentação Escolar e Agricultura Familiar : reconectando o consumo à produção. Saúde e Sociedade, 19(4), 933-945.

Triches, R. M., \& Silvestri, F. (2018). Adequação das chamadas públicas para aquisição de produtos da agricultura familiar para a alimentação escolar. Desenvolvimento Em Questão, 16(44), 233.

Vargas, A. (2017). Na perspectiva da qualidade ampla: os desafio e as oportunidades para a agricultura familiar frente às compras públicas. Universidade Federal do Paraná.

Vogt, S. P. C., \& Souza, R. S. (2009). Marcados institucionais locais como instrumento de fortalecimento da agricultura familiar: uma análise do Programa de Aquisição de Alimentos na região Celeiro - $R S$ (pp. 1-20).

W.K. Kellogg Foundation. (2004). Logic model development guide. In Logic Model Development Guide. W.K. Kellogg Foundation. 